\title{
Colégio Pedro II: democracia no ensino de línguas estrangeiras
}

\author{
Maria Gabriela Braga da Silva
}

Resumo: Este artigo pretende identificar o Colégio Pedro II como importante agente na democratização do ensino de línguas estrangeiras na educação pública brasileira na atualidade. Os projetos para a promoção do francês na instituição na década de 2010 são representativos dessa atuação. Com base em uma pesquisa documental, apresenta-se um panorama histórico das políticas linguísticas próprias ao Colégio Pedro II, em articulação com as políticas linguísticas educativas de âmbito nacional.

Palavras-chave: Colégio Pedro II. Glotopolítica. Políticas linguísticas. Línguas estrangeiras.

A presença das línguas estrangeiras (LE) no currículo da educação básica brasileira esteve, ao longo dos tempos, vinculada a diferentes fatores. Inicialmente associado a uma formação erudita própria das classes mais favorecidas, o conhecimento de LE hoje pode ser reconhecido como importante elemento na formação integral dos estudantes, tanto para a continuação dos estudos e atuação no mercado de trabalho quanto para o desenvolvimento do senso de alteridade, importante competência na contemporaneidade.

A despeito dessa importância, percebemos uma perda de espaço das disciplinas de LE no currículo da rede pública de ensino nos últimos tempos, com raras exceções. Da mesma forma, percebemos um desprestígio da diversidade de LE oferecidas na educação básica, uma vez que documentos como os editais do Enem e do PNLD contemplam apenas o inglês e o espanhol; o documento mais recente da educação brasileira, a BNCC, adota os termos "língua inglesa" no lugar da disciplina "língua

\footnotetext{
1 Professora do Departamento de Francês do Colégio Pedro II. Mestre em Estudos de Linguagem pela Universidade Federal Fluminense (UFF).
} 
estrangeira" prevista em publicações anteriores.

Neste contexto, este artigo apresenta a atuação do Colégio Pedro II (CPII) na promoção do ensino de línguas na educação brasileira, por meio de um panorama histórico das políticas linguísticas institucionais em articulação com as políticas linguísticas educativas de âmbito nacional. Em um segundo momento, identificamos as ações realizadas atualmente na instituição para a promoção do francês. Fundamentam a análise os conceitos de políticas linguísticas (CALVET, 2007), políticas linguísticas educativas (BEACCO; BYRAM, 2007) e glotopolítica (GUESPIN; MARCELLESI, 1986).

\section{O Colégio Pedro II}

Entre a chegada dos portugueses ao Brasil, em 1500, e o século XVIII, a instrução formal na colônia era oferecida por ordens religiosas. O sistema de ensino público e laico, advindo da Reforma pombalina de 1759, era lentamente implementado nas províncias. Apesar de importantes avanços no desenvolvimento do ensino superior no início do século XIX, em decorrência da instalação da família real portuguesa no Rio de Janeiro, a educação secundária no Brasil permanecia deficitária, sem a estrutura e a fiscalização necessárias (VIDOTTI, 2012).

Fundado em 1837 no Rio de Janeiro, o Colégio Pedro II (CPII) foi a primeira instituição oficial de ensino do Brasil. Uma instituição pública, porém não gratuita, que serviria à educação secundária dos filhos das classes favorecidas instaladas, principalmente, no Rio de Janeiro. Os Estatutos do colégio seriam a referência para as demais instituições de ensino secundário a serem criadas na capital e nas províncias.

Podemos afirmar que, a partir da criação do CPII, até o início do século XX, a história das políticas públicas educativas no Brasil se confunde 
com a história do colégio, em virtude de seu caráter de instituição modelo. Os Estatutos do CPII e outras resoluções relativas à instituição, seriam, durante muito tempo, os documentos oficiais da educação nacional.

O CPII veria seu status de instituição de referência vigorar até 1930, ano da criação do Ministério da Educação e Saúde Pública, órgão que regulamentaria os diferentes níveis de ensino (primário, secundário e superior) a partir de então. A instituição passaria por transformações administrativas e físicas ao longo do século XX: tornou-se autarquia federal em 1967 e passou por dois processos de expansão física, nos anos de 1950 e de 1980 .

Originalmente responsável pela formação secundária dos filhos da classe dominante da época, o CPII chega à segunda década do século XXI como uma instituição pública gratuita, com mais de 12 mil alunos na educação básica (da educação infantil ao ensino médio), divididos em 14 campi em diferentes regiões do estado do Rio de Janeiro, e mais de 700 alunos nos cursos de pós-graduação (lato sensu e stricto sensu) ${ }^{2}$. O CPII foi equiparado aos Institutos Federais de Educação, Ciência e Tecnologia em 2012 por força da Lei no 12.677 do mesmo ano. Conforme as políticas públicas de ações afirmativas em vigor desde o início dos anos 2000, o colégio tem reserva de vagas para alunos oriundos de escolas públicas, negros, pardos e indígenas, em vulnerabilidade social e/ou portadores de necessidades específicas.

\section{O ensino de línguas estrangeiras no CPII}

Tal como a história da educação nacional se confunde com a história do CPII, podemos dizer que a trajetória do ensino de LE na escola básica no Brasil pode também ser contada a partir da história do colégio. Assim,

2 Dados de 2018 disponíveis no site do Colégio Pedro II (http://www.cp2.g12.br/proreitoria/prodi/cpii_numeros). 
podemos dizer que os Estatutos do CPII, publicados via decretos entre 1838 e 1911, representavam a política linguística educativa do governo vigente.

O primeiro plano de estudos do CPII, publicado em 1838, apontava para um predomínio das disciplinas de humanidades, as quais representavam $70 \%$ da carga horária do curso completo, com ênfase no ensino de LE clássicas e modernas. Esses conhecimentos eram considerados necessários à formação de futuros doutores. Segundo Andrade,

A concepção humanística da educação, patrimônio cultural iluminista, privilegiava o conhecimento erudito do latim e das línguas estrangeiras, notadamente o francês, garantia de participação social no mundo civilizado; dos saberes clássicos da literatura, da retórica e da poética, formas de domínio do homem culto; e do conhecimento ilustrado da história universal, identificação da genealogia da nação brasileira branca, civilizada e cristã. (ANDRADE, 2015, p. 14).

Ao longo do século XIX as LE clássicas (latim e grego) e modernas (francês, inglês, alemão e italiano) ocuparam cerca de 50\% da carga horária total do curso secundário. $\mathrm{O}$ francês ocuparia $13 \%$ da carga horária total do curso secundário a partir de 1898, sendo oferecido em todas as séries do curso.

Após a Reforma educacional Francisco de Campos, em 1931, o CPII adotou um programa de ensino elaborado pelo recém-criado Ministério da Educação e Saúde Pública. O novo currículo para a educação nacional, cuja elaboração contou com a participação de professores catedráticos do colégio, incluía o ensino de latim, francês, inglês e alemão.

A Lei Orgânica do Ensino Secundário, publicada em 1942, reservaria importante espaço para as LE clássicas e modernas no currículo da educação básica. O latim, o grego, o francês, o inglês e o espanhol faziam parte do programa de estudos. A reforma educacional, conhecida como Reforma Gustavo Capanema, contaria também com a participação de professores 
catedráticos do CPII em sua elaboração (SANTOS et al., 2018, p. 53).

A partir de 1942, podemos identificar uma política própria para o ensino de línguas no CPII. Além das LE previstas no programa oficial do ensino secundário, o Departamento de Línguas Estrangeiras Modernas do colégio contava também com as cadeiras de alemão e italiano, conforme o Regimento interno publicado em 1953 (SANTOS et al., 2018, p. 110).

Com a publicação da Lei de Diretrizes e Bases da Educação (LDB) no 4.024 em 1961, o ensino de LE na educação básica deixou de ser obrigatório: a disciplina não era mencionada no texto da Lei. A nova legislação, entretanto, não teria impacto negativo no ensino de LE no CPII. Segundo o Regimento publicado através do Decreto no 55.235, de 1964, o CPII oferecia o francês e o inglês no ginásio, e o latim e o grego na opção do curso colegial clássico.

Durante o Regime Militar, uma nova LDB entraria em vigor: a Lei $n^{\circ} 5.692 / 71$. No texto da Lei, a disciplina Línguas Estrangeiras não é mencionada entre os componentes curriculares obrigatórios para $1^{\circ}$ e $2^{\circ}$ graus. No CPII, mais uma vez, não haveria prejuízo no currículo: durante toda a década de 1970, vigoraria o Regimento aprovado em 1968 (Decreto $\mathrm{n}^{\circ}$ 63.071/68), o qual listava, entre as disciplinas do curso secundário, as Línguas Clássicas e as Línguas Modernas Estrangeiras. A manutenção da oferta das disciplinas seria garantida por meio de dois concursos para admissão de professores de todas as cadeiras do CPII, realizados nos anos de 1970 e 1973 (SANTOS et al., 2018, p. 97). A disciplina Língua Estrangeira Moderna retomaria seu status de disciplina obrigatória na educação brasileira a partir da publicação da Resolução nº 58, em 1976. A Resolução previa a inclusão da disciplina em caráter obrigatório no núcleo comum do $2^{\circ}$ grau e recomendava sua inclusão no $1^{\circ}$ grau.

Os Programas Gerais de Ensino (PGE) do CPII, publicados em 1984, apresentavam a política institucional para o ensino de LE que se manteria até a década seguinte: duas LE modernas obrigatórias no currículo dos 
anos finais do $1^{\circ}$ grau, o francês e o inglês, e uma LE moderna obrigatória em todas as séries do $2^{\circ}$ grau, escolhida pelos alunos entre o francês, $o$ inglês, o espanhol e o alemão ${ }^{3}$ O latim, única LE clássica no currículo, seria oferecido em caráter obrigatório em apenas uma série do $1^{\circ}$ grau até o final dos anos 1990, quando foi retirado definitivamente da grade curricular.

Em 20 de dezembro de 1996 foi publicada a LDB no 9.394, também conhecida como Lei Darcy Ribeiro. Tratava-se do primeiro documento publicado após a abertura política de 1988 a traçar caminhos para a educação básica no país. A disciplina Língua Estrangeira Moderna voltava a aparecer na legislação como componente curricular obrigatório a partir da $5^{a}$ série (atual $6^{\circ}$ ano). Para o $2^{\circ}$ grau (atual Ensino Médio), a LDB também previa a inclusão de uma LE moderna como disciplina obrigatória e de uma segunda LE "em caráter optativo, dentro das possibilidades da instituição" (BRASIL, 1996). Ainda segundo o texto da Lei, a LE a ser ensinada seria escolhida pela comunidade escolar.

Simultaneamente à tramitação da LDB, eram elaborados os Parâmetros Curriculares Nacionais (PCN) pelo Ministério da Educação (MEC) com a contribuição de professores e outros especialistas da educação. Os volumes relativos ao primeiro e ao segundo segmentos do Ensino Fundamental (EF) vieram a público nos anos de 1997 e 1998, respectivamente. Os $\mathrm{PCN}$ tinham valor de "proposta de reorientação curricular” feita pelo MEC às secretarias de educação e instituições de ensino e pesquisa, atendendo à "necessidade de construção de uma educação básica voltada para a cidadania” (BRASIL, 1998a, p. 9).

A disciplina Língua Estrangeira aparece nos PCN como um componente equiparado às outras disciplinas do currículo, representando uma das oito áreas de conhecimento previstas para o EF. Os PCN resgatavam, assim, o direito de todo cidadão à aprendizagem de LE e a

3 O Alemão perderia seu status de opção de LE no $2^{\circ}$ grau nos anos 1990, quando se tornaria disciplina optativa, oferecida apenas em alguns campi da instituição. 
obrigação da escola de fornecê-la. Segundo o documento:

A Língua Estrangeira no Ensino Fundamental tem um valioso papel construtivo como parte integrante da educação formal. Envolve um complexo processo de reflexão sobre a realidade social, política e econômica, com valor intrínseco importante no processo de capacitação que leva à libertação. Em outras palavras, Língua Estrangeira no ensino fundamental é parte da construção da cidadania. (BRASIL, 1998b, p. 41).

Dois anos após a aparição dos PCN para o EF (PCNEF), foram lançados os PCN para o Ensino Médio (PCNEM), como uma proposta de reforma do ensino no segmento. $\mathrm{O}$ documento apresentava uma estrutura distinta daquele referente ao $\mathrm{EF}$, propondo a divisão dos componentes curriculares em apenas três áreas de conhecimento, a saber: Ciências Humanas e suas Tecnologias, Ciências da Natureza e suas Tecnologias e Linguagens, Códigos e suas Tecnologias, na qual estavam inseridos os Conhecimentos de Língua Estrangeira Moderna, junto àqueles de Língua Portuguesa, Educação Física, Artes e Informática (BRASIL, 2000a).

Encomendados a equipes diversas, os PCNEM apresentavam, além de uma redação e de uma estrutura distintas dos PCNEF, dissonâncias em relação à política de ensino de LE. Os PCNEF adotavam uma postura de pluralismo linguístico, sugerindo a promoção do ensino de várias línguas, segundo a escolha da comunidade escolar. Já os PCNEM, ao mesmo tempo em que apontavam para o "atendimento às diversidades", afirmavam: "é de domínio público a grande importância que o inglês e o espanhol têm na vida profissional das pessoas" (BRASIL, 2000b), sugerindo que outros idiomas que atendessem aos interesses da comunidade fossem oferecidos na escola no caso da inclusão de uma segunda LE, em caráter optativo.

Em 2002, foram publicados os PCN+ Ensino Médio - Orientações educacionais complementares aos PCN. O documento, que se propunha a 
manter atualizadas as diretrizes para a educação básica nacional, reforçava a valorização do ensino de LE na escola. Segundo o documento, "não há hoje como conceber um indivíduo que, ao término do ensino médio, prosseguindo ou não sua formação acadêmica, seja incapaz de fazer uso da língua estrangeira em situações da vida contemporânea" (BRASIL, 2002, p. 93).

É prudente assinalar que, ainda que o documento não sugira a adoção de uma LE em especial, a maioria dos exemplos listados nos PCN+ se refere ao ensino de língua inglesa. São indicadas técnicas de didática com nomenclaturas em inglês e há citações de obras em inglês sem a necessária tradução.

As importantes resoluções relativas à educação brasileira publicadas entre 1996 e 2002 não provocariam mudanças na oferta de LE no CPII. Como vimos, as LE já faziam parte da grade curricular obrigatória do EF e do Ensino Médio (EM) do colégio desde as décadas anteriores. Os PGE do CPII publicados em 1984 vigorariam até o ano de 2002, quando foi publicado o primeiro Projeto Político-Pedagógico (PPP) da instituição.

O PPP do CPII mantinha a obrigatoriedade do ensino do francês e do inglês aos alunos do EF e de uma LE no EM, escolhida pelos alunos entre o espanhol, o francês e o inglês. Essa dinâmica se manteria até o final do ano letivo de 2016.

Em agosto de 2005, foi promulgada a Lei $n^{\circ} 11.161$, ou a Lei do Espanhol, como ficou conhecida. A resolução tornava obrigatória a oferta da língua espanhola nos currículos de EM, restando a opção facultativa ao aluno. Para o EF, a inclusão da disciplina era optativa. Essa foi mais uma resolução que não afetaria o currículo do CPII, dado que o espanhol já era uma das opções de LE para os estudantes do EM.

As Ocem, Orientações Curriculares para o Ensino Médio, foram publicadas pelo MEC em 2006 como parte de um conjunto de ações do governo vigente à época para o desenvolvimento da educação básica no 
Brasil. Tratava-se de um "instrumento de apoio à reflexão do professor a ser utilizado em favor do aprendizado" (BRASIL, 2006, p. 6), sem valor de obrigatoriedade.

A seção do documento relativa ao ensino de LE reafirmava a importância da disciplina na educação básica, além de sua função na construção da noção de cidadania do educando na contemporaneidade, já mencionadas em diretrizes publicadas anteriormente. $\mathrm{O}$ documento apresentava ainda uma seção dedicada exclusivamente ao ensino de língua espanhola, em consonância com a Lei do Espanhol, publicada no ano anterior.

Assim como os $\mathrm{PCN}+$, as Ocem apresentavam reflexões e exemplos de atividades referentes ao ensino de língua inglesa, atentando para a sua aplicabilidade no ensino de outras LE.

Em 2013, o MEC publicou as novas Diretrizes Curriculares Nacionais para a Educação Básica (DCN). O documento mostrou-se inovador ao trazer orientações que contemplavam a educação infantil, o EF e o EM regulares, e outras modalidades de ensino, como a educação no campo, a educação indígena e a quilombola.

Quanto ao ensino de LE, as Diretrizes reforçavam a autonomia das instituições na escolha do idioma pela comunidade escolar, assegurada pela LDB, sem deixar de mencionar a oferta obrigatória do espanhol no EM, como previsto na Lei no $11.161 / 05$.

Em setembro de 2016, foi sancionada a Medida Provisória (MP) n ${ }^{\circ}$ 746 que, entre outras ações, alterava a política de ensino de línguas vigente em âmbito nacional. Alterando a LDB de 1996, a MP excluía a autonomia das comunidades escolares quanto à escolha do idioma a ser ensinado, revogava a Lei $\mathrm{n}^{\circ}$ 11.161/05 e instituía a inclusão obrigatória do inglês nos currículos de EM. Para o EF, a Medida previa a oferta do idioma. A MP $\mathrm{n}^{\circ}$ 746/16 seria convertida na Lei no 13.415 em 2017.

As resoluções advindas da MP reverberariam, ainda que de forma 
confusa, em uma mudança na política de ensino de LE do CPII. Enquanto a MP atribuía obrigatoriedade ao ensino de inglês no EM, a portaria interna no 222, de 10 de fevereiro de 2017, tornou o idioma obrigatório no EF. A partir de então, a segunda LE obrigatória cursada no segmento poderia ser escolhida pelos estudantes entre o espanhol e o francês. Essa opção, feita no $6^{\circ}$ ano, definiria a segunda LE cursada pelo aluno nos quatro anos finais do segmento. Não haveria mudanças na oferta de idiomas aos alunos do EM da instituição.

Em 16 de fevereiro do mesmo ano, foi publicada a Lei $\mathrm{n}^{\circ} 13.415$, que conferiria perenidade às resoluções elencadas na $M P \mathrm{n}^{\circ}$ 746/16. A Lei tratava ainda da Base Nacional Comum Curricular (BNCC), que vinha sendo elaborada desde 2014. Segundo a Lei, a BNCC deveria ser implementada em até dois anos a partir de sua homologação, a qual ocorreu em dois momentos: as seções referentes à Educação Infantil e ao EF foram homologadas em dezembro de 2017, e a seção referente ao EM foi validada em dezembro de 2018. Até o final do ano letivo de 2019 não houve nova alteração na PL institucional do CPII.

O Projeto Político-Pedagógico Institucional (PPPI) do CPII, publicado em 2018 com vigência até o ano de 2020, confirma a dinâmica de ensino de LE em voga na instituição desde a publicação da portaria interna no 222 , em 2017.

Entre os anos de 1990 e o início dos anos 2010, o ensino de LE no CPII esteve em conformidade com as resoluções de âmbito nacional vigentes no mesmo período. A oferta de mais disciplinas de LE do que aquelas previstas na LDB e em alguns documentos aponta para a existência de uma PL própria à instituição. A resolução institucional de 2017, a qual alteraria o status das LE oferecidas no EF do CPII, não implicaria prejuízos para o pluralismo linguístico característico do currículo da instituição. 
Segundo a proposta de Guespin e Marcellesi (1986), reconhecese como glotopolítica toda e qualquer ação sobre a linguagem, realizada em diversos âmbitos, sem distinção dos atores sociais envolvidos. Assim, “a glotopolítica engloba a política da língua: todos os casos de promoção, proibição, equipamento, mudança de status de uma língua são eminentemente fatos glotopolíticos; a política da língua é, então, um caso particular da glotopolítica [...]" (GUESPIN; MARCELLESI, 1986, p. 15, tradução nossa) ${ }^{4}$.

Sob essa ótica, identificamos que as práticas glotopolíticas do CPII na atualidade são orientadas por diversos atores. Por um lado, enquanto instituição pública federal, o colégio obedece às PL educativas expressas nos documentos que orientam a educação no Brasil: as Leis, os PCN, as OCEM e as DCN, entre outros.

Por outro lado, as práticas glotopolíticas realizadas no CPII são também a expressão de uma política própria para o ensino de línguas. Tal política é desenvolvida pelas diversas esferas da instituição e se manifesta em documentos (por exemplo, o PPPI) e na atuação conjunta de vários setores do colégio, notadamente pró-reitorias e o corpo docente, na execução de projetos desenvolvidos pelos departamentos pedagógicos.

4 La glottopolitique englobe la politique de la langue : tous les cas de promotion, interdiction, équipement, changement de statut d'une langue sont éminement des faits glottopolitiques; la politique de la langue est donc un cas particulier de la glottopolitique [...] (GUESPIN; MARCELLESI, 1986, p. 15). 
Figura 1 - Promoção de línguas estrangeiras no Colégio Pedro II

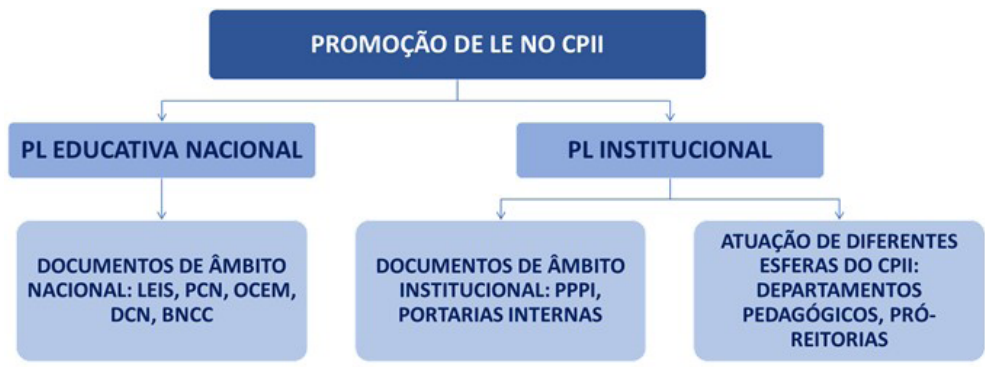

Fonte: Elaboração própria.

No caso do francês, o desenvolvimento de projetos para a promoção do idioma no CPII nos anos de 2010 foi possível graças às seguintes ações: atribuição da carga horária de docentes do Departamento de Francês para desenvolvimento de atividades de ensino, pesquisa e extensão; editais de apoio a eventos e publicações acadêmicas; fomento à iniciação científica; parcerias com instituições nacionais e internacionais para projetos de intercâmbio cultural para os alunos e de formação continuada para os docentes do Departamento.

Destacamos, além das atividades regulares em sala de aula, alguns dos projetos para a promoção do francês no CPII realizados entre 2010 e 2019:

DELF Scolaire: criado em 2006 por meio de uma parceria entre o CPII, o consulado da França no Rio de Janeiro e a Aliança Francesa do Rio de Janeiro, o projeto ofereceu a alunos a partir do $9^{\circ}$ ano aulas preparatórias para o exame de proficiência em língua francesa DELF Scolaire.

Mediatecas de Francês: entre 2014 e 2016, funcionaram as duas mediatecas de Francês do CPII, instaladas nos campi São Cristóvão III e Realengo. Durante esse período, foram oferecidas aos estudantes atividades como ateliês de teatro e grafite, oficina de produção textual e 
festivais de videoclipes e de curtas-metragens francófonos, além do acervo das mediatecas.

Jornadas de Estudos e Núcleo de Estudos Franco-Brasileiros (NEFB): em 2014 e 2015, professores do Departamento de Francês organizaram as Jornadas de Estudos ReFLEtindo, com a participação de professores-pesquisadores do CPII e de outras instituições brasileiras. A criação do NEFB em 2015 visava a fomentar estudos desenvolvidos por docentes do Departamento e viabilizar o surgimento de novas pesquisas. Contando com duas linhas de pesquisas (Literatura, discurso e identidade e Teorias linguísticas e ensino de francês no Brasil), desde sua criação o Núcleo realizou seminários e jornadas, além da publicação de livros com os trabalhos apresentados nos eventos.

Iniciação Científica Júnior: Professores do Departamento orientaram alunos do EF e do EM na realização de pesquisas no âmbito da língua francesa e das literaturas francófonas. Os alunos participantes foram contemplados com bolsas concedidas através de chamadas internas e, ao final do ano letivo, apresentaram seus trabalhos na Jornada de Iniciação Científica Júnior do CPII.

Curso de extensão "Francês instrumental": entre maio e dezembro de 2019, foi oferecido à comunidade, no campus Realengo, o curso de francês instrumental, que visava a preparar candidatos a exames de acesso a cursos de pós-graduação.

Material didático (MD): em virtude da ausência de materiais para o ensino de francês desenvolvidos por editoras brasileiras, há anos o Departamento de Francês do CPII adotava livros didáticos (LD) desenvolvidos por editoras francesas. A ausência da disciplina no Programa Nacional do Livro Didático (PNLD)5 e o alto custo do material importado levaram a instituição a um conjunto de medidas. A partir de

5 O programa distribui na rede pública de educação, desde 2011, LD das LE inglês e espanhol. 
2015, o setor de Assistência Estudantil do CPII efetuou a distribuição de LD de francês a alunos em situação de vulnerabilidade socioeconômica. Além disso, foi criado em 2017 o Grupo de Pesquisa e Elaboração de Material Didático (GPEMD), com o objetivo de substituir paulatinamente todo o MD importado por um material desenvolvido pelos professores do Departamento e viabilizado pela instituição. Desde a sua criação, o GPEMD desenvolve anualmente pelo menos um volume novo, além da revisão dos volumes produzidos nos anos anteriores.

\section{Considerações finais}

A análise dos documentos oficiais da educação brasileira publicados nas últimas décadas aponta para uma redução gradativa da diversidade de LE oferecidas no EF e no EM no país. Tal redução se tornou ainda mais explícita pela presença da disciplina "língua inglesa" (e não mais "língua estrangeira") nas publicações mais recentes, a Lei no ${ }^{\circ}$ 13.415/17 e a BNCC.

Lagares (2018, p. 67) assinala a motivação sociopolítica de tais resoluções. Segundo o autor, a substituição da autonomia dos estados e dos municípios na escolha da LE a ser ensinada nas escolas, prevista na LDB de 1996, pela imposição do ensino do inglês no EM, estaria ligada à política externa do governo brasileiro, diretamente alinhada aos Estados Unidos. Ainda que tais resoluções tratassem do ensino de línguas, seus objetivos eram visivelmente não linguísticos.

A despeito das alterações mais recentes na PL educativa brasileira, as quais apontam para uma uniformização do ensino de LE no país, percebemos que no CPII continuou a vigorar uma política própria de pluralidade na oferta da disciplina. A instituição manteve em sua grade curricular obrigatória o ensino de duas LE no EF e, no EM, uma LE escolhida pelos estudantes entre o espanhol, o francês e o inglês.

A atuação de diferentes esferas do CPII para a promoção do 
ensino de idiomas, notadamente do corpo docente dos departamentos de disciplinas de LE, ilustra a proposta de Troncy (2011, p. 7), segundo a qual as PL não são prerrogativas apenas do Estado, mas também de grandes atores coletivos que disponham dos recursos para a implementação de tais políticas.

\section{Referências}

ANDRADE, Vera Lúcia C. Q. Apresentação. Cadernos de História da Educação, Uberlândia, v. 14, n. 1, p. 13-18, jan/abr 2015. Disponível em: http:// www.seer.ufu.br/index.php/che/article/view/32109/17459. Acesso em: 26 jul. 2021.

BEACCO, Jean-Claude; BYRAM, Michael. De la diversité linguistique à léducation plurilingue. Guide pour l'élaboration des politiques linguistiques éducatives en Europe. Strasbourg : Conseil de l'Europe, 2007.

BRASIL. Lei $n^{\circ}$ 4.024, de 20 de dezembro de 1961. Fixa as Diretrizes e Bases da Educação Nacional. Brasília, DF: Câmara dos deputados, [1961]. Disponível em: https://www2.camara.leg.br/legin/fed/lei/1960-1969/lei-4024-20-dezembro-1961-353722-publicacaooriginal-1-pl.html. Acesso em: 19 mar. 2019.

. Decreto $n^{\circ}$ 55.235, de 17 de dezembro de 1964. Aprova o Regimento do Colégio Pedro II. Brasília, DF: Presidência da República, [1964]. Disponível em: https://www2.camara.leg.br/legin/fed/decret/1960-1969/ decreto-55235-17-dezembro-1964-395677-publicacaooriginal-1-pe.html. Acesso em: 19 mar. 2019. 
. Decreto $n^{\circ}$ 63.071, de 5 de agosto de 1968. Aprova o Regimento do Colégio Pedro II. Brasília, DF: Presidência da República, [1968]. Disponível em: https://www2.camara.leg.br/legin/fed/decret/1960-1969/decreto-63071-5-agosto-1968-404190-publicacaooriginal-1-pe.html. Acesso em: 19 mar. 2019.

. Lei $n^{\circ}$ 5.692, de 11 de agosto de 1971. Fixa Diretrizes e Bases para o ensino de $1^{\circ}$ e $2^{\circ}$ graus, e dá outras providências. Brasília, DF: Câmara dos deputados, [1971]. Disponível em: https://www2.camara.leg.br/legin/fed/ lei/1970-1979/lei-5692-11-agosto-1971-357752-publicacaooriginal-1-pl. html. Acesso em 19 mar. 2019.

. Resolução $n^{\circ}$ 58, de 22 dezembro de 1976. Altera dispositivos da Resolução n. 8 de $1^{\circ}$ de dezembro de 1971, e dá outras providências. Brasília, DF: Conselho Federal de Educação, [1976]. Disponível em: https:// www.histedbr.fe.unicamp.br/pf-histedbr/resolucao_n.58-1976_altera_dispositivos_da_resolucao_n._8.pdf. Acesso em: 26 jul 2021.

. Lei $n^{\circ}$ 9.394, de 20 de dezembro de 1996. Estabelece as diretrizes e bases da educação nacional. Brasília, DF: Presidência da República, [1996]. Disponível em: http://www.planalto.gov.br/ccivil 03/LEIS/L9394.htm. Acesso em: 19 mar. 2019.

. Secretaria de Educação Fundamental. Parâmetros curriculares nacionais: Ensino Fundamental. Brasília: MEC, 1998a.

. Secretaria de Educação Fundamental. Parâmetros curriculares nacionais: Terceiro e quarto ciclos do Ensino Fundamental: Língua Estrangeira. Brasília: MEC, 1998b.

- Secretaria de Educação Média e Tecnológica. Parâmetros curriculares nacionais: Ensino Médio. Parte I: Bases Legais. Brasília: MEC, 2000a. 
BRASIL. Secretaria de Educação Média e Tecnológica. Parâmetros curriculares nacionais: Ensino Médio. Parte II: Linguagens, Códigos e suas Tecnologias. Brasília: MEC, 2000b.

PCN + Ensino Médio. Orientações curriculares complementares aos Parâmetros Curriculares Nacionais. Linguagens, Códigos e suas Tecnologias. Brasília: MEC, 2002.

. Lei $n^{\circ} 11.161$, de 5 de agosto de 2005. Dispõe sobre o ensino da língua espanhola. Revogada pela Lei no 13.415/17. Brasília, DF: Presidência da República, [2005]. Disponível em: http://www.planalto.gov.br/ccivil 03/ Ato2004-2006/2005/Lei/L11161.htm. Acesso em: 19 mar. 2019.

- Secretaria de Educação Básica. Orientações curriculares para o ensino médio. Volume 1: Linguagens, códigos e suas tecnologias. Brasília: MEC, 2006.

. Lei no 12.677, de 25 de junho de 2012. Dispõe sobre a criação de cargos efetivos, cargos de direção e funções gratificadas no âmbito do Ministério da Educação, destinados às instituições federais de ensino; altera as Leis $\mathrm{n}^{\circ} \mathrm{s} 8.168$, de 16 de janeiro de 1991, 11.892, de 29 de dezembro de 2008, e 11.526, de 4 de outubro de 2007; revoga as Leis nº 5.490, de 3 de setembro de 1968, e 5.758, de 3 de dezembro de 1971, e os Decretos-Leis $\mathrm{n}^{\text {os }} 245$, de 28 de fevereiro de 1967, 419, de 10 de janeiro de 1969, e 530, de 15 de abril de 1969; e dá outras providências. Brasília, DF: Presidência da República, [2012]. Disponível em: http://www.planalto.gov.br/ccivil_03/_ ato2011-2014/2012/lei/112677.htm. Acesso em: 26 jul. 2021.

. Secretaria de Educação Básica. Diretrizes curriculares nacionais da educação básica. Brasília: MEC, SEB, DICEI, 2013. Disponível em: http:// portal.mec.gov.br/docman/julho-2013-pdf/13677-diretrizes-educacao-basica-2013-pdf/file. Acesso em: 9 jan. 2019. 
. Ministério da Educação. Base Nacional Comum Curricular. Brasília: MEC, 2018. Disponível em: https://bit.ly/39idHpe. Acesso em: 24 nov. 2020.

- Medida Provisória $n^{\circ} 746$, de 2016. Institui a Política de Fomento à Implementação de Escolas de Ensino Médio em Tempo Integral, altera a Lei $n^{\circ}$ 9.394, de 20 de dezembro de 1996, que estabelece as diretrizes e bases da educação nacional, e a Lei $n^{\circ} 11.494$ de 20 de junho 2007, que regulamenta o Fundo de Manutenção e Desenvolvimento da Educação Básica e de Valorização dos Profissionais da Educação, e dá outras providências. Convertida na Lei no 13.415 de 2017. Brasília, DF: Presidência da República, [2016]. Disponível em: http://www.planalto.gov.br/ccivil 03/ Ato20152018/2016/Mpv/mpv746impressao.htm. Acesso em: 22 jan. 2019.

BRASIL. Lei $n^{\circ} 13.415$, de 16 de fevereiro de 2017. Altera as Leis $n^{\circ}$ 9.394, de 20 de dezembro de 1996, que estabelece as diretrizes e bases da educação nacional, e 11.494, de 20 de junho 2007, que regulamenta o Fundo de Manutenção e Desenvolvimento da Educação Básica e de Valorização dos Profissionais da Educação, a Consolidação das Leis do Trabalho - CLT, aprovada pelo Decreto-Lei no 5.452, de $1^{\circ}$ de maio de 1943, e o Decreto-Lei $\mathrm{n}^{\mathbf{0}}$ 236, de 28 de fevereiro de 1967; revoga a Lei $\mathrm{n}^{\mathbf{0}} 11.161$, de 5 de agosto de 2005; e institui a Política de Fomento à Implementação de Escolas de Ensino Médio em Tempo Integral. Brasília, DF: Câmara dos deputados, [2017]. Disponível em: https://www2.camara.leg.br/legin/fed/lei/2017/ lei-13415-16-fevereiro-2017-784336-publicacaooriginal-152003-pl.html. Acesso em: 19 mar. 2019.

CALVET, Louis-Jean. As Políticas Lingüísticas. São Paulo: Ipol/Parábola Editorial, 2007. 
COLÉGIO PEDRO II. Plano geral de ensino 1984. Rio de Janeiro: [s.n.], 1984.

COLÉGIO PEDRO II. Plano geral de ensino 1996. Rio de Janeiro: [s.n.], 1996.

. Projeto Político-pedagógico. Brasília: Inep/MEC, 2002. Disponível em: https://bit.ly/2HHWnMw. Acesso em: 27 fev. 2019.

Portaria $n^{\circ} 2.911$, de 16 de setembro de 2016. Estende o oferecimento da disciplina da Língua Espanhola para o Ensino Fundamental. Rio de Janeiro, 2016. Disponível em: http://www.cp2.g12.br/images/comunicacao/2016/Setembro/portaria 2911.pdf. Acesso em: 19 mar. 2019.

Portaria $n^{\circ}$ 222, de 10 de fevereiro de 2017. Inserção da Língua Espanhola no Ensino Fundamental. Rio de Janeiro, 2017. Disponível em: http://www.cp2.g12.br/images/comunicacao/2017/FEV/portaria 222.pdf. Acesso em: 19 mar. 2019.

. Projeto Político-pedagógico Institucional 2017/2020. Rio de Janeiro: [s.n.], 2018. Disponível em: https://bit.ly/2uekfQ3. Acesso em: 27 fev. 2019.

GUESPIN, Louis ; MARCELLESI, Jean-Baptiste. Pour la glottopolitique. Langages, [S.I.], v. 21, n. 83, p. 5-34, 1986. Disponível em: https://doi. org/10.3406/lgge.1986.2493. Acesso em: 26 jul. 2021.

LAGARES, Xoán Carlos. Qual política linguística?: desafios glotopolíticos contemporâneos. São Paulo: Parábola, 2018.

SANTOS, Beatriz B. M. et al. Memória histórica do Colégio Pedro II: 180 anos de história na educação do Brasil. Rio de Janeiro: Colégio Pedro II, 2018. 
TRONCY, Christel. Les politiques linguistiques entre cloisonnements et renouveaux épistémologiques ? In: ANALELE UNIVERSITĂȚII DIN BUCUREȘTI, ȘTIINȚE POLITICE, 13, n. 1, 2011. București: Universității din București, p. 35-53, 2011. Disponível em: https://www.ssoar.info/ssoar/ handle/document/37734. Acesso em: 26 jul. 2021.

VIDOTTI, Joselita Júnia V. Políticas linguísticas para o ensino de língua estrangeira no Brasil no século XIX, com ênfase na língua inglesa. 2012. 245 f. Tese (Doutorado em Letras) - Faculdade de Filosofia, Letras e Ciências Humanas, Universidade de São Paulo, São Paulo, 2015.

Pedro II School: democracy in additional language teaching

Abstract: This paper aims at presenting Pedro II School as an important agent in the democratization of additional language teaching in Brazilian public education today. The projects employed in order to promote the French language in the institution in the 2010s are representative of this agency. Based on documentary research, we present a historical panorama of institutional language policies, particular to Pedro II School, in articulation with educational language policies on a national basis.

Keywords: Pedro II School. Glottopolitics. Language policies. Additional language.

Recebido em: 28/11/2020

Aceito em: 05/03/2021 